http://jmscr.igmpublication.org/home/ ISSN (e)-2347-176x ISSN (p) 2455-0450

crossref DOI: https://dx.doi.org/10.18535/jmscr/v7i9.112

Journal Of Medical Science And Clinical Research

\title{
Changing Trends in Retinopathy of Prematurity Profile in A Tertiary Care Centre in India
}

Authors

\section{Dr Miloni Shah ${ }^{1 *}$, Dr Kalpana Singh ${ }^{2}$, Dr Mrunall Borrse ${ }^{3}$, Dr Pranjali Pawar ${ }^{4}$}

${ }^{1}$ MS Ophthalmology, Dr.Vasantrao Pawar Medical College and Research Centre, Adgaon. Nashik 422207. India ${ }^{2}$ MS Ophthalmology, Vitreo-Retinal surgeon, Assistant Professor, Dr.Vasantrao Pawar Medical College and Research Centre, Adgaon. Nashik 422207 India

${ }^{3,4}$ MS Ophthalmology, Dr.Vasantrao Pawar Medical College and Research Centre, Adgaon. Nashik 422207. India Corresponding Author

Dr Miloni Shah

Permanent Address: 601, Manju Castle, 51- A St. Xavier's Road, Vile Parle West. Mumbai 400056. India

\begin{abstract}
Background: To conduct an effective ROP screening program according to the National Neonatology Forum (NNF) and to identify the infants who could benefit from treatment and make appropriate recommendations on the timing of future screening.

Aims and Objectives: To estimate the incidence of ROP among Premature infants.

Material and Methods: A Prospective Observational study of 2 year in which 170 patients were screened with following criteria:GA at birth of $\leq 35$ weeks, $B W<1700 \mathrm{gms}$, exposed to oxygen > 30days, other factors that can increase the risk of ROP and where screening should be considered are premature babies $>37$ weeks and $>1700 \mathrm{gms}$. The first screening was done within 4 weeks (30 days) of life in infants with age $>28$ weeks of GA, 2-3 weeks after birth if GA $<28$ weeks or BW is $<1200 \mathrm{gms}$

Results: Out of the 170 babies screened 35 babies had ROP. Incidence of ROP in our study was 20.59\%. Mean BW of ROP babies was $1528.94 \pm 334.59 \mathrm{~g}$. Mean GA at birth of ROP babies was $32.31 \pm 2.38$ weeks, (range 26-39 weeks). Using the current AAP screening guidelines ( $\leq 1500 \mathrm{~g} \mathrm{BW}$ or $\leq 32$ weeks GA) 8 babies (16 eyes) i.e $22.85 \%$ would have been missed. 11 eyes of 6 babies $(68.75 \%)$ would have been missed if UKRCPH were used.

Conclusion: ROP may be seen in heavier and larger babies in India that have consequently a shorter window period for development of ROP.

Keywords: Retinopathy of Prematurity, Screening, Gestational Age, Birth Weight.
\end{abstract}

\section{Introduction}

Retinopathy of Prematurity (ROP), seen in the premature and low Birth Weight (BW) infant is a vasoproliferative disorder of the developing retinal vasculature and is a potentially blinding condition.
The World Health Organization's "Vision 2020 programme" has identified ROP as an important cause of blindness in both high and middle income countries.

Approximately 2 million babies out of 26 million annual live births in India are born with BW $<2000$ $\mathrm{g}$ and are at risk of developing ROP. ${ }^{[1]}$ 
WHO estimates that there are 15 million preterm births a year (born at $<37$ weeks) and India has the largest number of preterm births in the world. ${ }^{[2]}$ The incidence of ROP is increasing in India because of improved neonatal survival rate. In India the incidence of ROP is between 38 and $51.9 \%$ in low birth infants. ${ }^{[1,3]}$

Very few comprehensive review articles covering all the aspects of ROP are published. Also, due absence of large epidemiological studies and mapping of nationwide ROP data, the present study was undertaken with a wider screening criteria to screen the premature infants for ROP which if left untreated would have resulted in severe visual disability.

\section{Material and Methods}

Study Type: Prospective observational study

Study Settings: Department of Ophthalmology of Dr.Vasantarao Pawar Medical College and Research Centre.

Study Duration: August 2016 to September 2018 Study Population: All the infants fitting into the Inclusion criteria admitted in our NICU and also those referred from outside attending OPD were screened from August 2016- September 2018.

\section{Eligibility Criteria \\ Selection of Subjects}

All neonates weighing $<1700 \mathrm{gm}$ and/ or with a gestation $\leq 35$ weeks admitted to Neonatal ICU(NICU) of our Tertiary Care Centre and also those referred from outside attending our OPD were routinely screened for ROP between the year August 2016- September 2018.All relevant perinatal data was undertaken

(Inclusion Criteria according to National Neonatology Forum (NNF) Guidelines ${ }^{[1]}$

- Gestational Age (GA) at birth of $\leq 35$ weeks

- Birth Weight $(\mathrm{BW})<1700 \mathrm{~g}$

- Exposed to oxygen $>30$ days

- Other factors that can increase the risk of ROP and where screening was done are premature babies $>37$ weeks and $>1700 \mathrm{~g}$ but with
1. Respiratory Distress Syndrome

2. Sepsis

3. Sickly survivors

4. Pneumonitis

5. Multiple blood transfusions

6. Multiple births(twins/triplets)

7. Apnoeic episodes

8. Intraventricular haemorrhages

\section{Exclusion Criteria}

- Babies with Congenital anomalies of eye

- Babies with chorioretinitis

- Infants born after 36 weeks (excluding the above condition)

- $\quad$ BW>1700 g (excluding the above causes)

\section{Methodology}

Informed consent was taken from the parents/guardian.

Institutional Ethical Committee approval was taken. (IEC- 42/2016-2107)

Patients were chosen according to the inclusion and exclusion criteria.

Detailed maternal history and neonatal history was taken.

All infants were screened by the same ophthalmologist.

\section{Time of Screening}

The first screening was done within 4 weeks (30 days) of life in infants with age $>28$ weeks of GA, 2-3 weeks after birth if GA is $<28$ weeks or BW is $<1200 \mathrm{~g}$. ${ }^{[5]}$

\section{Examination}

- Screening was done under a radiant warmer in the NICU, under the guidance of the neonatologist. Discharged and stable babies were screened in the outpatient department (OPD). Parents/ Guardians were informed before the examination about the procedure of screening and after their consents the infants were screened. Pupils were dilated using diluted $0.5 \%$ tropicamide plus $2.5 \%$ phenylephrine eye drops in 1:2 dilution using distilled water 2-3 times about 10-15 minutes apart or till 
full dilatation occurs. Care was taken to wipe off the excess drops to prevent systemic absorption though the cheek skin.

- Topical anaesthesia 2\% proparacaine drops was instilled. A pediatric wire speculum was used to keep the eyes apart. Gentle indentation with a pediatric scleral depressor was used to stabilize the globe.

- A detailed Anterior segment and Posterior Segment Evaluation:

- Follow up schedule for ROP Babies was done accordingly. ${ }^{[4]}$

- Retinal examination was terminated based on post conceptional age or retinal findings. Examination was terminated when

1. Full retinal vascularization was noted which was usually completed around 4045 weeks

2. Regression of ROP noted

The babies were screened every 1-2 weeks at least until the infant is $38-40$ weeks of postconceptional age.

\section{Statistical Analysis}

A SPSS software was used for all statistics A P value $<0.05$ was considered as statistically significant

\section{Results}

During the study period of 2 years from August 2016- September 2018 the total number of babies screened were 177.

Out of the 177 babies that we screened 170 babies were included in our study.116 males $(68.24 \%)$ and 54 Females $(31.76 \%)$. The mean BW of the babies in our study was $1590 \mathrm{~g} \pm 368.19 \mathrm{~g}$ (Range: $898-3000 \mathrm{~g})$. Mean GA of the babies in our study was 33.38 \pm 2.8 weeks (Range: 25-41 weeks).

35 of the 170 babies had ROP. Thus, the incidence of ROP in our study was $20.59 \%$.

\section{ROP Data}

Initial examination was done between 3 and7 weeks with an average of 4 weeks. Late screening may be due to delayed referral of the baby from outside or late admission in our NICU and failure to screen outside.

Total males with ROP were 26 (74.28\%), females with ROP $9(25.71 \%)\{\mathrm{p}<0.05)$

\section{Incidence and Severity of ROP in Relation to BW}

The mean BW of NON ROP babies was $1606.58 \pm 375.92 \mathrm{~g}$. Mean BW of ROP babies was $1528.94 \pm 334.59$ g (range: $898-2750 \mathrm{~g})\{\mathrm{p}<0.05\}$. [Table 1]

Table 1 Distribution of ROP Babies According. to BW

\begin{tabular}{lc|c|c} 
BW & $\begin{array}{c}\text { TOTAL } \\
\text { BABIES }\end{array}$ & $\begin{array}{c}\text { ROP NEGAT IVE } \\
\text { EYES (N=270) }\end{array}$ & $\begin{array}{c}\text { ROP POSIT IVE } \\
\text { (EYES)(N=70) }\end{array}$ \\
\hline$=1000$ & 5 & $8(2.9 \%)$ & $2(2.8 \%)$ \\
\hline $1001-1250$ & 21 & $28(10.3 \%)$ & $14(20 \%)$ \\
\hline $1251-1500$ & 57 & $90(33.33 \%)$ & $24(34.2 \%)$ \\
\hline $1501-1750$ & 46 & $74(27.4 \%)$ & $18((25.57 \%)$ \\
\hline $1751-2000$ & 27 & $46(17.03 \%)$ & $8(11.42 \%)$ \\
\hline$>2001$ & 14 & $24(8.8 \%)$ & $4(5.7 \%)$ \\
\hline
\end{tabular}

Incidence of ROP in Relation to GA at Birth: Mean GA at birth of NON ROP babies was $33.91 \pm 2.81$ week. Mean GA at birth of ROP babies was $32.31 \pm 2.38$ weeks, (range 26-39 weeks). ( $\mathrm{p}<0.05)$. [Table 2]

Table 2 Distribution of ROP According to GA at Birth

\begin{tabular}{|l|c|cc|}
$\begin{array}{l}\text { GA IN } \\
\text { WEE KS }\end{array}$ & $\begin{array}{c}\text { TOTAL } \\
\text { BABIES }\end{array}$ & $\begin{array}{c}\text { ROP } \\
\text { NE GATIVE } \\
\text { E YES (N=270) }\end{array}$ & $\begin{array}{c}\text { ROP POSITIVE } \\
\text { (EYES) } \\
(\mathbf{N}=70)\end{array}$ \\
\hline$=28$ & 13 & $20(7.4 \%)$ & $6(8.5 \%)$ \\
\hline $29-30$ & 10 & $12(4.44 \%)$ & $8(11.4 \%)$ \\
$31-32$ & 33 & $42(15.5 \%)$ & $24(34.28 \%)$ \\
$33-34$ & 61 & $96(35.5 \%)$ & $26(37.14 \%)$ \\
$35-36$ & 27 & $50(18.51 \%)$ & $4(5.71 \%)$ \\
$37-38$ & 21 & $42(15.5 \%)$ & 0 \\
$39-40$ & 4 & $6(22 \%)$ & $2(2.8 \%)$ \\
$>40$ & 1 & $2(0.7 \%)$ & 0 \\
\hline
\end{tabular}

First Detection of ROP: 23(65.71\%) babies had ROP in $1^{\text {st }}$ screening. $1 / 25$ baby had AP ROP and was lasered the same day. In 12(34.28\%) babies the peripheral retinal was avascular which then 
developed ROP. 1/12 babies had later developed PLUS disease.

The mean $\mathrm{BW}$ at $1^{\text {st }}$ detection of ROP was 1557.14 grams and average Post Conceptional Age was 37.08 weeks.

\section{Asymmetry}

Out of 35 ROP babies (70 eyes), 3 babies ( 6 eyes) had asymmetrical disease. None of the babies in our study had unilateral presentation

\section{Data According to the Stages}

21 (30\%) eyes had Stage I, 18 eyes (25.7\%) had Stage II, 27 eyes(38.6\%) had Stage III, 2 eyes (2.8\%) had Aggressive Posterior ROP (APROP) and 2 eyes $(2.8 \%)$ had Plus disease. The BW and GA at birth were inversely proportional. [Table 3]

Table 3 Distribution of Mean BW and GA According to the stages of ROP Seen

\begin{tabular}{|l|cc|c|}
\hline & STAGE I & ST AGE II & $\begin{array}{c}\text { STAGE III, PLUS } \\
\text { DISEASE AND AP ROP }\end{array}$ \\
\hline MEAN BW(GRAMS) & $1660 \pm 428$ & $1567.5 \pm 238.8$ & $1435.5 \pm 309.7$ \\
\hline MEAN GA(WEEKS) & $32.4 \pm 1.58$ & $33.55 \pm 2.51$ & $31.56 \pm 2.56$ \\
\hline
\end{tabular}

(in case of asymmetrical disease, the higher staging was considered).

\section{Zone Distribution}

4 eyes $(5.71 \%)$ had ROP in Zone I,14(20\%) eyes had ROP in Zone II and 52(74.28\%) eyes had ROP in Zone III. Maximum cases in our study was seen in Zone III.

\section{Neonatal Risk Factors}

Various neonatal risk factors were studied of which $\mathrm{O} 2$ exposure, number of days of $\mathrm{O} 2$ exposure, Ventilation, number of days on ventilation, RDS, Sepsis, Blood transfusion, Apnoea using Chi-Square test were significant indicating an increased association of ROP.[Table 4]
Table 4 Details of the Risk Factors

\begin{tabular}{|c|c|c|c|c|}
\hline NEONAT AL RISK FACTORS & 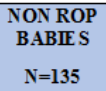 & $\begin{array}{c}\text { ROP } \\
\text { BABIIS } \\
\text { N=35 }\end{array}$ & P VALUE & SIGNIFICANCE \\
\hline O2 EXPOSURE & 85 & 32 & 0.00119 & SIGNIFICANT \\
\hline $\begin{array}{l}\text { AVERAGE NO OF DAYS OF } \\
\text { O2 EXPOSURE }\end{array}$ & 8.152 & 33.09 & 0 & SIGNIFICANT \\
\hline VENTILATION & 11 & 9 & 0.00404 & SIGNIFICANT \\
\hline $\begin{array}{l}\text { AVERAGE NO OF DAYS OF } \\
\text { MECHANICAL VENTILATION }\end{array}$ & 2.18 & 8.44 & 0.009 & SIGNIFICANT \\
\hline PHOTOTHERAPY & 25 & 6 & 0.8510 & NOT SIGNIFICANT \\
\hline MUL TIPLE BIRTH & 28 & 5 & 0.389 & NOT SIGNIFICANT \\
\hline RDS & 57 & 26 & 0.00072 & SIGNIFICANT \\
\hline SEPSIS & 28 & 18 & 0.00021 & SIGNIFICANT \\
\hline SICKLY SURVIVORS & 30 & 7 & 0.776477 & NOT SIGNIFICANT \\
\hline PNEUMONITIS & 33 & 8 & 0.844 & NOT SIGNIFICANT \\
\hline BLOOD TRANSFUSION & 18 & 10 & 0.0303 & SIGNIFICANT \\
\hline IVH & 1 & 1 & 0.3007 & NOT SIGNIFICANT \\
\hline APNEA & 12 & 11 & 0.00051 & SIGNIFICANT \\
\hline
\end{tabular}

For Multivariate Analysis we applied Binary Logistic Regression analysis. We found that the number of days of $\mathrm{O} 2$ exposure and Sepsis was a significant risk factor. Analysis showed that increasing day of $\mathrm{O} 2$ exposure is associated with an increased likelihood of ROP. [Table5]

Table.5 Showing Binary Logistic Regression

\begin{tabular}{|c|c|c|c|c|c|}
\hline \multirow[t]{2}{*}{ RISK FACTORS } & \multirow[t]{2}{*}{ P VALUE } & \multicolumn{2}{|c|}{$\begin{array}{l}\text { 95\%CONFIDENCE } \\
\text { NTERVAL }\end{array}$} & \multirow[t]{2}{*}{ SIGNIFICANCE } & \multirow[t]{2}{*}{$\begin{array}{l}\text { ODD } \\
\text { RATIC }\end{array}$} \\
\hline & & UPPER & LOWER & & \\
\hline EXPOSURE TO OXYGEN & 0.081 & 0 & 1.62 & NOT SIGNIFICANT & 0.02 \\
\hline DAYS OF 02 & 0.002 & 1.192 & 2.186 & SIGNIFICANT & 1.614 \\
\hline MECHANICAL VENTILATION & 0.201 & 0 & $3.30 \mathrm{E}+01$ & NOT SIGNIFICANT & 0.001 \\
\hline $\begin{array}{lrl}\text { DAYS } & \text { ON } & \text { MECHANICAL } \\
\text { VENTILATION } & \end{array}$ & 0.406 & 0.22 & 41.996 & NOT SIGNIFICANT & 3.041 \\
\hline MUL TIPLE BIRTH & 0.292 & 0.356 & 30.918 & NOT SIGNIFICANT & 3.317 \\
\hline PHOTOTHERAPY & 0.057 & 0.926 & 258.368 & NOT SIGNIFICANT & 15.47 \\
\hline RDS & 0.694 & 0.062 & 64.776 & NOT SIGNIFICANT & 2.009 \\
\hline SEPSIS & 0.016 & 1.839 & 374.782 & SIGNIFICANT & 26.256 \\
\hline SICKLY SURVIVOR & 0.873 & 0.035 & 17.183 & NOT SIGNIFICANT & 0.777 \\
\hline PNEUMONITIS & 0.198 & 0.001 & 4.338 & NOT SIGNIFICANT & 0.061 \\
\hline BLOOD TRANSFUSION & 0.293 & 0.196 & 220.855 & NOT SIGNIFICANT & 6.579 \\
\hline IVH & 0.31 & 0.001 & $3.97 \mathrm{E}+09$ & NOT SIGNIFICANT & 1892.2 \\
\hline APNEIC EPISODES & 0.685 & 0.033 & 182.589 & NOT SIGNIFICANT & 2.44 \\
\hline
\end{tabular}

Using the current American Association of Paediatrics (AAP) guidelines $(\leq 1500 \mathrm{~g} \mathrm{BW}$ or $\leq 32$ weeks GA) 8 babies (22.85\%) would have been missed.

So out of total 31 eyes of 16 babies (one baby had only one eyed lasered) that were lasered, 4 eyes of 2 babies (12.9\%) would have been missed if AAP guidelines were used. Thus, the Sensitivity of AAP guidelines was $77.14 \%$

If the UK Royal College of Paediatrician and Child Health (UKRCPCH) would have been used an additional 6 babies would have been missed.

So out of total 31 eyes of 16 babies (one baby had only one eyed lasered) that were lasered, 11 eyes 
of 6 babies $(68.75 \%)$ would have been missed if UKRCPH guidelines were used.

Thus, the sensitivity of UKRCPH guidelines was $60 \%$.

\section{Discussion}

The increasing incidence of prematurity and better survival of smaller babies has led to an increase in the incidence of ROP. Hence an attempt was made in current study to look at the incidence of ROP in a rural based Tertiary Care Centre.

In the present study, a total of 170 babies were screened in detail.

\section{Incidence}

In our present study the incidence of ROP was $20.59 \%$. Incidence of severe ROP (all which required treatment) was $9.41 \%$. International studies suggest incidence of ROP ranges from 10$45 \%$. In India, approximately, the incidence of ROP is reported between $24 \%$ and $47 \%$. $^{\text {[5] }}$

The incidence in our study was on the lower side of the range found in India. This might probably be due to the fact that the neonatal care centre in our hospital provided controlled delivery of oxygen to the premature at-risk babies.

\section{Mean BW and GA}

Mean BW of ROP vs Non ROP babies was $1528.94 \pm 334.59 \mathrm{~g} \quad$ vs $1606.58 \pm 375.92 \mathrm{~g}$ respectively and mean GA of ROP vs Non ROP babies was $32.31 \pm 2.38$ vs $33.91 \pm 2.81$ weeks(range: 26-39).

A study done by HUNGI et al ${ }^{[6]}$ in which the mean BWs and periods of gestation with and without ROP were1555.9 vs. $1672.5 \mathrm{~g}$ and 32.2 vs. 34.6 weeks, respectively. Also, a study done by Sundar K.C et $\mathrm{al}^{[7]}$ also found that the mean BW and GA of babies with and without ROP was 1480 grams vs 1620 grams and 32 vs 33 weeks respectively.

\section{First Detection of ROP}

$23 / 35(65.71 \%)$ babies had ROP in $1^{\text {st }}$ screening. In $12 / 35$ (34.28\%) babies the peripheral retinal was avascular which then developed ROP. The average BW of all ROP babies at first detection was 1557.14 g. Average Post Conceptional Age at first detection of all ROP was 37.08 weeks.

Higgins et $\mathrm{al}^{[8]}$ Rekha et $\mathrm{a}^{[9]}$ reported that most severe stage was reached at a range 31-41 weeks and 37-42 weeks PCA respectively

\section{Stage Wise Distribution of ROP}

In our study we noticed as the Stage of ROP increased the average BW decreased. This was similarly notice by Rohit Charan, M R Dogra et al. $^{[10]}$

\section{Zone Distribution of 70 Eyes}

$2(2.8 \%)$ eyes had ROP in Zone I,14(20\%) eyes had ROP in Zone II and 54(77.1\%) eyes had ROP in ZONE III. Few babies in Zone I may be due to regular screening and early identification of all severe ROP and also may be due to poor survival rate of very low $\mathrm{BW}$ infants.

CRYSTAL Le et $\mathrm{al}^{[11]}$ in their study found out patients with ROP most commonly in ZONE III $(68 \%)$ and zone II was the second most common (26\%) and only one case was noted in Zone I. Also, Jasmina Alajbegovic-Halimic et al ${ }^{[12]}$ stated in their study that the babies with ROP was most commonly found to have ROP in Zone III $(62.5 \%)$.

\section{Neonatal Risk Factors}

We investigated role of various risk factors listed. Applying Chi Square test of significance on Univariate analysis $\mathrm{O} 2$ exposure, number of days of $\mathrm{O} 2$, mechanical ventilation, number of days on mechanical ventilation, RDS, sepsis, blood transfusion and apnoea were found to be significant.

Applying Binary Logistic Regression multivariate analysis showed Number of days on $\mathrm{O} 2$ and Sepsis were statistically significant. A detailed study of $\mathrm{O} 2$ exposure in our study revealed that the average number of days on $\mathrm{O} 2$ in ROP babies was 33.09 days and that in NON ROP babies was 8.152 days

This was similar to studies conducted by Andrea Moraes et al ${ }^{[13]}$ and Krishna A Rao et al ${ }^{[14]}$

Using the current AAP screening guidelines ( $\leq$ $1500 \mathrm{~g}$ BW or $\leq 32$ weeks GA) 8 babies (16 eyes) i.e $22.85 \%$ would have been missed. 11 eyes of 6 
babies $(68.75 \%)$ would have been missed if UKRCPH were used. Studies from India have shown that children with BW of $2000 \mathrm{~g}$ can develop ROP. ${ }^{[15,16,17]}$ About $6.7 \%$ and $13.3 \%$ of severe ROP would have been missed using the UKRCPH or AAP screening criteria, respectively ${ }^{[16]}$ Another study from South India noted that $17.7 \%$ and $22.6 \%$ of children with threshold ROP or worse would have been missed if they were to use the AAP or RCO screening criteria, respectively. ${ }^{[17]}$

\section{Conclusion}

As seen in this study and many studies conducted in India ROP does occur in larger and heavier babies. Moreover, these babies have a very short window period for development of ROP. An early identification of these heavy babies at risk for developing severe ROP would help to reduce the burden of blindness associated with ROP.

We require a more definitive guideline rather than a discretionary one to include more and more babies so as to not miss out on any babies with ROP and to limit the burden of blindness caused by ROP.

For current scenario, the cut off for BW and GA need to be higher and a regionalisation of the screening criteria needs to evolve.

\section{Financial support and sponsorship: Nil.}

Conflicts of interest: There are no conflicts of interest.

Declaration of patients consent: The authors certify that they have obtained all appropriate patient's parent(s)/guardian consent forms. In the form the patient's parent(s)/ guardian has/ have given his/her/their consent for his /her/their data and other clinical information to be reported to the journal. The patient's parent(s)/ guardian understands that their names and initial will not be published and due efforts will be made to conceal their identity, but anonymity cannot be guaranteed.

Declaration of Ethics Committee: The authors certify that they have obtained ethical clearance from the Institutional Ethical Committee (IEC42/2016-2107).

Availability of Data and Material: All data generated or analysed during this study are included in this manuscript attached as a separate supplementary information file.

Competing Interest: Not Applicable

Funding: Not applicable

Author's Contribution:

Dr.Miloni Shah: Conception, Design of the work, Analysis, Interpretation of data

Dr. Kalpana Gadsingh: Conception, Acquisition of data

Dr. Mrunall Borrse: Analysis, Interpretation of data

Dr. Pranjali Pawar: Analysis, Design of work

Acknowledgement: The Authors thank Mr. Sunil Patil and Mr. Rakesh Patil for assisting with the data analysis.

\section{References}

1. Pejawar R, Vinekar A, Bilagi A. National Neonatology Foundation's Evidence-based Clinical Practise Guidelines (2010), Retinopathy of Prematurity, NNF India, New Delhi 2010:253-62

2. Howson CP, Kinney MV, Lawn JE, editors. March of Dimes, PMNCH, Save the Children, WHO. Born Too Soon: The Global Action Report on Preterm Birth. Geneva: World Health Organization; 2012. Back to cited text no. 4

3. Jalali S, Anand R, Kumar H, Dogra MR, Azad R, Gopal L. Programme planning and screening strategy in retinopathy of prematurity. Indian $\mathrm{J}$ Ophthalmol. 2003;51(1):89-99.

4. American Academy of Pediatrics, Section on Ophthalmology. Screening examination of premature infants for retinopathy of prematurity. Pediatrics ; 117: 572-576.

5. Murthy KR, Murthy PR, Shah DA, Nandan MR, S NH, Benakappa N. Comparison of profile of retinopathy of prematurity in semi urban/rural and urban 
NICUs in Karnataka, India. $\mathrm{Br} \mathrm{J}$ Ophthalmol2013;97:687-9. Back to cited text no. 5

6. Hungi B, Vinekar A, Datti N, Kariyappa P, Braganza S, Chinnaiah $S$, et al. Retinopathy of prematurity in a rural Neonatal Intensive Care Unit in South India - A prospective study. Indian $\mathbf{J}$ Pediatr. 2012;79:911-5.

7. Sundar KC, Devi Meenakshi K, Patil AB. A retrospective study on the risk factors for retinopathy of prematurity in NICU of tertiary care hospital. Int J ContempPediatr2018;5:1447-51.

8. Higgins RD, Mendelsohn AL, DeFeo MJ, Ucsel R, Hendricks-Munoz KD. Antenatal dexamethasone and decreased severity of retinopathy of prematurity. Arch Ophthalmol. 1998;116:601-5.

9. Rekha S, Battu RR. Retinopathy of prematurity: incidence and risk factors. Indian Pediatr 1996; 33: 999-1003.

10. Charan R, Dogra MR, Gupta A, Narang A. The incidence of retinopathy of prematurity in a neonatal care unit. Indian J Ophthalmol. 1995;43:123-6.

11. Le C, Basani LB, Zurakowski D, Ayyala RS, Agraharam SG. Retinopathy of prematurity: Incidence, prevalence, risk factors, and outcomes at a tertiary care center in Telangana. J Clin Ophthalmol Res 2016;4:119-22.

12. Alajbegovic-Halimic J, Zvizdic D, Alimanovic-Halilovic E, Dodik I, Duvnjak S. Risk Factors for Retinopathy of Prematurity in Premature Born Children. Med Arch. 2015;69(6):409-13.

13. Freitas AM, Mörschbächer R, Thorell MR, Rhoden EL. Incidence and risk factors for retinopathy of prematurity: a retrospective cohort study. Int $J$ Retina Vitreous. 2018;4:20. Published 2018 May 31. doi:10.1186/s40942-018-0125-z

14. Rao KA, Purkayastha J, Hazarika M, Chaitra R, Adith KM. Analysis of prenatal and postnatal risk factors of retinopathy of prematurity in a tertiary care hospital in South India. Indian $J$ Ophthalmol. 2013;61(11):640-4.

15. Gopal L, Sharma T, Ramchandran S. Retinopathy of prematurity: A study. Indian J Ophthalmol1995;43:59-61.

16. Jalali S, Matalia J, Hussain A, Anand R. Modification of screening criteria for retinopathy of prematurity in India and other middle-income countries. Am J Ophthalmol2006;141:966-8.

17. Vinekar A, Dogra MR, Sangtam T, Narang A, Gupta A. Retinopathy of prematurity in Asian Indian babies weighing greater than 1250 grams at birth: Ten-year data from a tertiary care center in a developing country. Indian J Ophthalmol2007;55:3316.
Abbreviations
ROP- Retinopathy Of Prematurity
BW- Birth Weight
GA- Gestational Age
NICU- Neonatal Intensive Care Unit
NNF- National Neonatology Forum
APROP- Aggressive Posterior Retinopathy of Prematurity
UKRCPH- UK Royal College of Paediatrician and Child Health
OPD- Out Patient Department 